\title{
Photochemical smog effects in mixed conifer forests along a natural gradient of ozone and nitrogen deposition in the San Bernardino Mountains
}

\author{
Michael Arbaugh*, Andrzej Bytnerowicz, Nancy Grulke, Mark Fenn, \\ Mark Poth, Patrick Temple, Paul Miller
}

USDA Forest Service, Pacific Southwest Research Station, Riverside Forest Fire Laboratory, 4955 Canyon Crest Drive, Riverside, CA 92507-6099, USA

\begin{abstract}
Toxic effects of photochemical smog on ponderosa and Jeffrey pines in the San Bernardino Mountains were discovered in the 1950s. It was revealed that ozone is the main cause of foliar injury manifested as chlorotic mottle and premature needle senescence. Various morphological, physiological and biochemical alterations in the affected plants have been reported over a period of about 40 years of multidisciplinary research. Recently, the focus of research has shifted from studying the effects of ozone to multiple pollutant effects. Recent studies have indicated that the combination of ozone and nitrogen may alter biomass allocation in pines towards that of deciduous trees, accelerate litter accumulation, and increase carbon sequestration rates in heavily polluted forests. Further study of the effects of multiple pollutants, and their long-term consequences on the mixed conifer ecosystem, cannot be adequately done using the original San Bernardino Mountains Air Pollution Gradient network. To correct deficiencies in the design, the new site network is being configured for long-term studies on multiple air pollutant concentrations and deposition, physiological and biochemical changes in trees, growth and composition of over-story species, biogeochemical cycling including carbon cycling and sequestration, water quality, and biodiversity of forest ecosystems. Eleven sites have been re-established. A comparison of 1974 stand composition with data from 2000 stand composition indicate that significant changes in species composition have occurred at some sites with less change at other sites. Moist, high-pollution sites have experienced the greatest amount of forest change, while dryer low-pollution sites have experienced the least amount of stand change. In general, ponderosa pine had the lowest basal area increases and the highest mortality across the San Bernardino Mountains.
\end{abstract}

Published by Elsevier Science Ltd.

Keywords: Multiple pollutants; Pine; Ozone; San Bernardino Mountains; Stand composition

\section{Introduction}

Asher (1956) observed and described unexplained foliar symptoms on ponderosa pine. He named the condition ' $\mathrm{x}$ disease'. A field experiment using branch chambers was designed to examined the relationship between urban smog containing high levels of ozone and visible foliar symptoms on ponderosa pine needles (Miller et al., 1963). This field experiment and later ozone fumigations of ponderosa pine seedlings (Richards et al., 1968) confirmed that ozone was the cause of the chlorotic mottle and early abscission of affected needles.

\footnotetext{
* Corresponding author. Tel.: +1-909-680-1564; fax: +1-909-680-1501

E-mail address: marbaugh@deltanet.com (M. Arbaugh).
}

Subsequently, between 1968 and 1974, a series of longterm monitoring sites were established to study trends in crown injury to ponderosa and Jeffrey pines from oxidant air pollution in the San Bernardino Mountains. Over the past 30 years, studies conducted at these sites have contributed to our understanding of foliar injury and bole growth responses to ozone exposure in forest systems. More recently, the scope of research efforts at these sites has expanded to include studies on nitrogen deposition to ecosystems, and multiple effects of ozone and $\mathrm{N}$ deposition on ecosystem function.

Diverse studies have been conducted using the San Bernardino Mountains Gradient Study (SBGS) network. The original forest stand level, ozone foliar injury studies were reported by Miller and Elderman (1977) and Miller et al. (1982, 1989). Additional studies reported include physiological responses (Grulke, 1999), deposition of 
multiple pollutants to forest canopies (Bytnerowicz et al., 1999), nitrogen saturation (Fenn et al., 1996), stream water nitrate export trends (Fenn and Poth, 1999), and biochemical changes (Tausz et al., 2000). Most of this work was summarized in the Report Oxidant Air Pollution Impacts in the Montane Forests of Southern California: A case study of the San Bernardino Mountains (Miller and McBride, 1999). The report summarized the first 40 years of research in the San Bernardino Mountains.

Work since then has begun to examine the effects of multiple pollutants on carbon allocation and sequestration, and soil chemistry (Arbaugh et al., 1999; Grulke et al., 1998, 1999). These studies indicate that ozone and nitrogen may cause a shift in pine tree foliar biomass allocation towards that of deciduous trees (Grulke and Balduman, 1999) and acceleration of litter accumulation (Arbaugh et al., 1999; Takemoto et al., 2001). The nitrogen may also cause an increase in stream water nitrate levels (Fenn and Poth, 1999). These changes may lead to eventual replacement of pines by more nitrophilous shade and ozone tolerant tree species (Miller et al., 1982; Minnich, 1999).

During the 25 years since their establishment, substantial disturbances and forest development have occurred at SBGS sites. Several sites were located on private land where avoidance of disturbance was not possible. At many of the original sites, only a portion of the original trees can still be identified. Both management and insect/disease disturbances have resulted in the abandonment or addition of trees to about a third of the sites. Rapid forest growth, due to fire suppression and nitrogen deposition, has occurred at the western end of the mountains but not at the eastern end. These disturbances, along with the lack of sufficient lowpollution impact sites and changing research emphasis, have reduced the usefulness of this gradient system.

Re-establishment of these sites is needed if continued research is to be conducted in the future. Understanding long-term effects of chronic air pollution exposure on natural systems and biogeochemical changes in the soilplant system are facilitated with long-term data. The SBGS sites represent some of the oldest forest air-pollution effect sites in the world and, therefore, are a resource of great importance to both the U.S. Forest Service and those doing research in air pollution. This paper describes the approach taken to rehabilitate the SBGS sites to make them more useful in a variety of research studies. These studies will provide an updated research emphasis and will include some initial study results of stand changes over the 25 years since the sites were established.

\section{Historical site design and uses}

Between 1968 and 1974, 18 study sites were established across a west to east gradient of air pollution in the San Bernardino Mountains. An additional 22 sites were established around Blue Jay, CA, to examine the role of topography on crown injury (Arbaugh et al., 1999). Seedling and sapling study sites were also established at six sites across the San Bernardino Mountains. Between 1988 and 1998 additional sites were established for two major studies, funded, respectively, by the U.S. Environmental Protection Agency (Grulke, 1999) and the California Air Resources Board (Air Resources Board, 1998).

The original 18 SBGS site locations were selected following ground inspection and available information on distribution of photochemical smog, soil condition, forest composition, and stand/tree health. The prospective sites were first located by discovering stands of ponderosa and Jeffrey pine where at least 50 trees with $\mathrm{dbh} \geq 30 \mathrm{~cm}$ were present on flat or gently sloping terrain; the terrain did not change in terms of aspect or drainage. The second decision point was to measure out a series of adjoining $30 \times 30$-m sites to determine if the 50-tree sample could be located on uniform land and soil conditions. The stand was rejected if the presence of bark beetle activity was excessive or if needle insect activity or root disease centers of Heterobasidion annosum $(\mathrm{Fr} / \mathrm{Fr})$ Bref. were detected.

If these criteria were met, a point of origin was established and a compass bearing for a site centerline was determined. Essentially, the line was in the direction of the maximum extent of uniform site conditions, including the presence of a suitable number of pines $\geq 30 \mathrm{~cm} \mathrm{dbh}$. Within the $30-\mathrm{m}$ width of the site, the 50 pines $\geq 30 \mathrm{~cm} \mathrm{dbh}$ and all other trees, that were at least $10 \mathrm{~cm} \mathrm{dbh}$, were assigned a numbered metal tag. The tag was nailed at head height on the side of the tree facing towards the centerline. The distance out from the origin and the distance to the right or left of the centerline was measured (to the nearest $0.1 \mathrm{~m}$ ) for each tagged tree. Finally, a strip $3-\mathrm{m}$ wide $(1.5 \mathrm{~m}$ on each site of the centerline) was surveyed to tally seedling trees for all species $\geq 1-\mathrm{m}$ tall but $\leq 10 \mathrm{~cm} \mathrm{dbh}$. The dbh of each tree was measured. For seedlings, $\leq 1-\mathrm{m}$ tall the height was measured in centimeters.

Fire scars or mechanical damage to stems $\geq 10 \mathrm{~cm} \mathrm{dbh}$ was noted along with the presence of mistletoes (dwarf and true). Elytroderma needle disease (Elytroderma deformans (Weir) Darker) of pines and any minor insect pest (scale) or other diseases were noted, if present.

The dominant over-story species present in the SBGS sites consisted of ponderosa pine (Pinus ponderosa Dougl.), Jeffrey pine (Pinus jeffreyi Grev. and Balf.), white fir (Abies concolor Gord. and Glend.), and California black oak (Quercus kelloggii Newb.). At many sites, there were occasional Sugar pine (Pinus labertiana Dougl.), and at a few sites incense cedar (Calocedrus decurrens Torrey) was an important component of stand composition.

Each year (from 1974 through 1978) and periodically at later dates, including 1984 and 1988, the stem diameter and 
ozone injury to crowns of all ponderosa or Jeffrey pines $(\geq 10 \mathrm{~cm} \mathrm{dbh})$ were determined at all sites. Mortality was tallied for all species in size classes $\geq 10 \mathrm{~cm}$ dbh. Since 1992, crown condition and stem growth data has only been gathered at subsets of sites, culminating with the final measurements at seven sites prior to re-establishing new sites.

\section{Requirements and constraints for the new SBGS network}

The original sites were intended to monitor crown injury and tree diameter changes due to the effects of ozone. Future uses of this network of sites will focus on multiple pollutant effects, and interactions between pollutants and other biotic and abiotic stressors that affect forest health. In addition, the new network needs to be less oriented along a single pollutant gradient and more towards enabling the construction of spatially explicit surfaces of ambient pollutant concentrations, stand growth, species composition, and biogeochemistry.

While the information from the more recently established sites (those established between 1988 and 1998) is important, older sites have a temporal record that is rare in air pollution research. The study site design and experimental treatments of newer sites also differ enough to reduce comparability of results with the older sites. Therefore, the original 18 SBGS sites were used as the foundation for the new spatial gradient system.

\section{Design changes}

The new design is intended to preserve the ability to use all sites in a spatial surface, while recognizing differences in species composition, precipitation and soils that occur across small distances in the San Bernardino Mountains. This will be accomplished by establishing a network of sites expanding in two directions along the air pollution gradient. This two dimensional 'grid' of sites will extend both north and south (perpendicular to air pollution flow) as well as east and west (parallel to the air pollution flow). The advantage of this approach is that large-scale comparisons based on geography, exposure, and species composition are possible, while accommodating opportunities for smaller scale studies requiring more homogenous forest conditions. It should be noted that forest composition changes are greatest in the west to east direction of the gradient.

Alternative sub-groupings of sites, based on other environmental factors, are also possible. Soil, geology, climate, historical management, and insect and disease information can be used to form different sub-groups of comparable sites. Data layers are not yet available to develop these groups, but will be added as they become available.
In the original design for the sites, the length of the site was predicated on the area needed to obtain 50 ponderosa/ Jeffrey pines with $\mathrm{dbh} \geq 30 \mathrm{~cm}$. This approach led to a disparity in the total number of trees tagged between sites, some sites containing fewer than 100 trees while others contained more than 300 trees. While the emphasis of future studies will maintain crown evaluation as a component, we anticipate that studies will also encompass diverse investigations of ecosystem structure and change, and function compared with historical studies. Accordingly, the maximum number of tagged trees will be fixed at 300 per site for newly established sites. If there are fewer than 50 ponderosa and Jeffrey pines in this group, then additional ponderosa/ Jeffrey pines will be tagged beyond the site to obtain the required number to conduct the crown injury surveys. We anticipate this will only be necessary on the western side of the mountain, where large numbers of white fir and incense cedar have appeared as a result of fire suppression and photochemical smog effects in mixed conifer forests. Every effort will be made to include tagged trees from the original sites in the new sites.

In the original sites, site boundaries will be retained unless there are management, insect and disease, or recreational impacts that reduce the value of the area for representing general forest structure, function, and change in the area where they are located. If the original site is partially disturbed, then that part of the original site that is still usable will be retained in the new site. If a disturbance has occurred at one end of the site, the old boundary will be extended along the existing centerline in the other direction to include a sufficient numbers of trees in the new site.

\section{Vegetation changes determined by re-established SBGS sites}

During the winter of 2000, 11 sites were re-established along the original gradient. Many of these sites required boundary changes to permit an adequate tree number for the new network design. Portions of five sites were abandoned due to pest, recreation, and management impacts. The 11 reestablished sites were located throughout the San Bernardino Mountain Range. General patterns of vegetation change indicated that basal area growth rates were lowest for ponderosa and Jeffrey pine, and highest for white fir and incense cedar (Table 1). Overall mortality rates were highest for ponderosa pine, followed by white fir, black oak and Jeffrey pine. In-growth (changes in stems/ha) also indicates that white fir, sugar pine and incense cedar (at moist sites) were the species that had increased the most on the sites.

The 11 re-established sites can be categorized into three groups. A group of three sites (BP, CP, DWA) are located along the western and southern edge of the area (Fig. 1). These sites have both the highest productivity and air pollution of the SBGS sites, receiving unobstructed onshore flow from the Pacific Ocean across the Los Angeles 
Table 1

Changes in surviving tree species for all SBGS sites between 1974 and 2000

\begin{tabular}{llcc}
\hline Species & \multicolumn{2}{l}{$\begin{array}{l}\text { Surviving trees } \\
\text { num }\end{array}$} & $\begin{array}{c}\text { \% Change in } \\
\text { basal area/ha }\end{array}$ \\
\cline { 2 - 3 } & $\begin{array}{l}\text { Number of } \\
\text { surviving trees }\end{array}$ & \% Mortality & \\
\hline Black oak & 90 & 33 & 103.6 \\
Incense cedar & 27 & 7 & 273.1 \\
Jeffrey pine & 148 & 29 & 61.6 \\
Ponderosa pine & 278 & 46 & 76.4 \\
Sugar pine & 8 & 7 & 333.5 \\
White fir & 41 & 35 & 285.8 \\
\hline
\end{tabular}

Basin; they will be referred to as the High sites in the following discussion. They are also characterized by being located near rural communities that occupy the majority of forest along the south and west edge of the mountain range. All sites show impact by recreation users such as hikers, campers, and those riding horses or bicycles. Very little of this area, however, has been used for organized recreational activities, such as group camps or established backpacking trails, due to the small area of forested land available.

Five other sites (CA, TUN, SV, BF, CAO) are located in the interior of the mountain range (Intermediate sites). These sites have lower soil moisture, productivity, and air pollution than southern sites, but higher than sites located along the northern and eastern edge of the range. These sites also have had the greatest disturbances from management and recreation, partially due to their location in highly desirable interior mountain locations. All sites are located near hiking trails or organized camping areas. As a result, impacts from insect and diseases, salvage logging, hazard tree removal and mechanical fuel reductions have been high for this group, resulting in significant numbers (as much as 73\%) of the original site trees being removed or dying during the study period.

The final group of three sites (NGV, HV and $\mathrm{HB}$ ) are located in northern and eastern sides of the range that receive less precipitation and air pollution than the other sites (low sites). These areas are more distant from population centers, which may have contributed to reduced management and recreation impacts over the past 25 years. Dispersed recreation, such as off-road vehicles, bicycling and hiking are common in these areas, but at less frequent intensities than areas near rural communities and population centers (south and western sites).

\section{Forest changes over 25 years}

Overall, the greatest increase in basal area at sites was due to increased numbers and size of white fir (Table 1). Black oak and sugar pine also had high growth rates where they occurred. The lowest overall basal area increases were

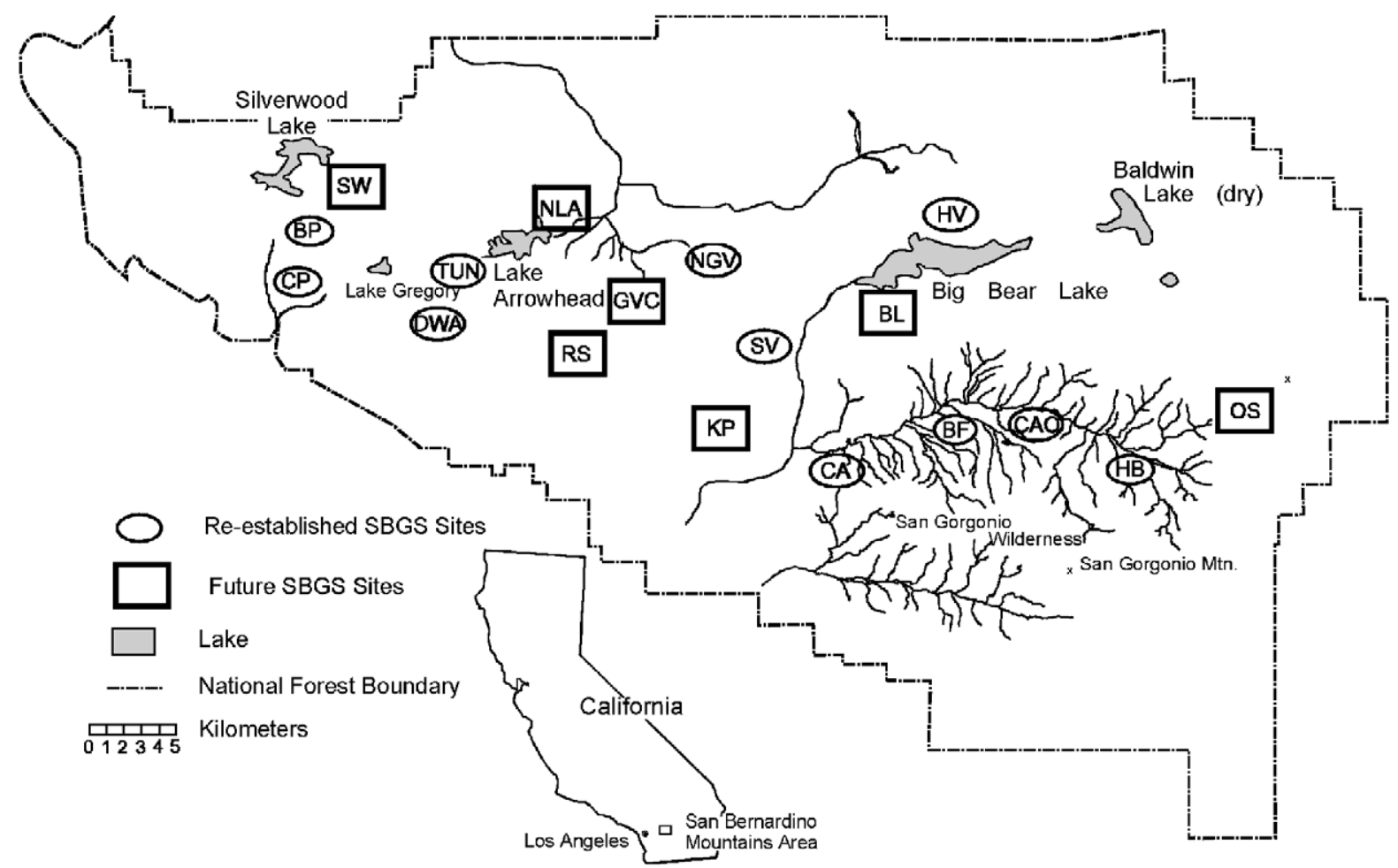

Fig. 1. Map of new SBGS site locations. Existing sites used for this study: CP-Camp Pavika, BP—Breezy Point, DWA—Dogwood A, TUN—Tunnel 2, NGV - North Green Valley, SV-Snow Valley, BL-Bluff Lake, HV-Holcome Valley, CA—Camp Angeles, BF-Barton Flats, CAO-Camp Osceola, HB - Heart Bar. Additional sites to be added to the system: SW—Silverwood Lake, NLA—North Lake Arrowhead, RS—Running Springs, GVC—Green Valley Creek, KP_Keller Peak, OS—Onyx Summit. 
Table 2

Changes in stand composition of sites between 1974 and 2000

\begin{tabular}{|c|c|c|c|c|c|c|c|c|c|}
\hline \multicolumn{4}{|c|}{ Changes in original SBGS sites between 1974 and 2000} & \multicolumn{6}{|c|}{ Differences between original and new SBGS sites } \\
\hline \multirow[t]{2}{*}{$\begin{array}{l}\text { Sites } \\
\end{array}$} & \multirow[t]{2}{*}{ Mortality (\%) } & \multirow{2}{*}{$\begin{array}{l}\text { Basal area } \\
\text { changes (\%) }\end{array}$} & \multirow{2}{*}{$\begin{array}{l}\text { Management } \\
\text { actions }\end{array}$} & \multicolumn{5}{|c|}{ Basal area changes $(\%)$} & \multirow[t]{2}{*}{ Stems/ha $(\%)$} \\
\hline & & & & $\mathrm{PP}$ & JP & WF & IC & BO & \\
\hline \multicolumn{10}{|c|}{ High precipitation and pollution (High) } \\
\hline $\mathrm{BP}$ & 27.8 & 84.0 & None & 55.4 & np* & NS** & 132.2 & 83.9 & 47.5 \\
\hline $\mathrm{CP}$ & 33.1 & 79.0 & None & 66.7 & np & np & np & 74.2 & -39.0 \\
\hline DWA & 22.1 & 236.9 & None & 132.1 & np & 513.3 & 414.0 & 179.2 & 138.7 \\
\hline \multicolumn{10}{|c|}{ Intermediate precipitation and pollution (Intermediate) } \\
\hline $\mathrm{CA}$ & 39.2 & 127.3 & Hazard & 46.1 & np & 343.6 & $\mathrm{np}$ & 54.9 & 26.6 \\
\hline $\mathrm{BF}$ & 34.9 & 82.1 & None & 77.3 & 100.0 & NS & $\mathrm{np}$ & 59.6 & 72.0 \\
\hline $\mathrm{CAO}$ & 52.3 & 61.7 & Thinning & 38.2 & 58.0 & 399.0 & np & 42.3 & -13.4 \\
\hline SV & 72.8 & 47.5 & Salvage & NP & 45.1 & 111.9 & np & np & -70.2 \\
\hline TUN & 47.7 & 204.6 & Salvage, Thinning & 59.2 & np & 562.6 & NS & 239.0 & 149.2 \\
\hline \multicolumn{10}{|c|}{ Low precipitation and pollution (Low) } \\
\hline HB & 6.9 & 73.5 & None & NP & 72.3 & 82.5 & $\mathrm{np}$ & np & 25.2 \\
\hline HV & 8.7 & 70.3 & None & NP & 63.9 & 152.8 & NS & 38.0 & 34.4 \\
\hline NGV & 12.3 & 42.6 & None & NP & 28.1 & 183.7 & np & np & 43.7 \\
\hline
\end{tabular}

The left side of the table compares tree information of original sites between 1974 and 2000. The right side of the table compares differences between 1974 (original sites) with 2000 (re-established sites).

* np-not present.

** NS-new species in re-established sites (compared with surviving trees in original site).

for ponderosa and Jeffrey pine. Ponderosa pine had the lowest basal area increase at 10 of the 11 sites where it occurred, and the highest mortality rates over all of the sites. Jeffrey pine had slightly higher basal area increases and lower mortality than ponderosa pine, but basal area increases were still lower than other tree species at the sites.

The most consistent difference between the three groups of sites was in mortality rates (Table 2). Low sites had little mortality over the study period, while mortality at High sites had approximately twice that found in the Low sites. Intermediate sites had the highest mortality of any group, but most of the mortality was connected with insect mortality, sanitation, salvage and understory thinning treatments conducted during the 1980 s.

Basal area changes of surviving trees were variable between the three groups, but absolute increases in basal area were much greater at High sites than at Low sites. Changes were variable at the Intermediate sites, largely due to differences in local environmental conditions and management treatments.

In-growth was also greatest for the High group, except at $\mathrm{CP}$ where only ponderosa pine and black oak occurred. Incense cedar and white fir both increased between $132 \%$ and $513 \%$ at these sites. Competing species basal area (white fir or incense cedar) increased an average of $480 \%$ faster than ponderosa pine basal area at these sites.

Low sites had smaller basal area growth increases and ingrowth rates relative to other sites (Table 2). Mortality was very low at these sites and, although basal area changes were large for surviving trees, actual basal area increases were small compared with the High sites. Competing species increased an average of $240 \%$ faster than Jeffrey pine at these sites. These patterns are consistent with previous reports of vegetation change (Minnich et al., 1993; Minnich, 1999) and are likely due to the long-term effects of active fire suppression that have been present in the San Bernardino Mountains since the 1930s.

There was little pattern for Intermediate site in-growth. This was the result of the large amount of stand disturbance due to mortality caused by insects, thinning by management, and removal of over story trees. Two sites (CAO and SV) had reduced densities in the newly established plots. Low seedling regeneration rates are the likely cause for these reduced densities. At the SV site, National Forest management personnel had planted seedlings in an attempt to increase tree density, with little success (Arbaugh, personnel communication).

\section{Conclusions}

Stand composition of the SBGS sites has clearly changed over the past 25 years. The pattern of composition change is dominated by increased growth and in-growth of white fir, sugar pine and incense cedar (at moist sites), and lower growth rates and in-growth of ponderosa and Jeffrey pine. Identifying a specific effect of air pollution on stand composition is complex, due to the multiple gradients of ozone, nitrogen deposition and precipitation. Stand density increased at sites with high ozone, $\mathrm{N}$ deposition and precipitation due to the faster growth of ozone and shade tolerant species (white fir and incense cedar) at the expense of more susceptible species such as ponderosa pine. Dryer 
sites with low ozone and $\mathrm{N}$ deposition had little mortality, less in-growth, and smaller changes in species composition than other sites.

The long-term changes at these sites also indicate that ponderosa pine may be at more risk from air pollution than Jeffrey pine. Ponderosa pine occurs at sites with high productivity and pollution in the San Bernardino Mountains, resulting in more rapid forest changes than at low productivity and pollution sites where Jeffrey pine occurs.

Additional site information is needed before patterns of forest change, suggested by these sites, can be confirmed. The relationship needs to be quantified between stand composition and multiple pollutants. The additional seven sites, to be added to the SBGS sites, should add important information to the trends suggested by the sites established to date. The results of this study also illustrate the complexity of local forest responses to multiple environmental stressors.

\section{References}

Arbaugh MJ, Johnson DW, Pulliam WM. Simulated effects of N deposition, ozone injury and climate change on a forest stand in the San Bernardino Mountains: chapter 16. In: Miller PR, McBride JR, editors. Oxidant air pollution impacts in the montane forests of Southern California. Ecol. Studies, vol. 134. New York (NY): Springer; 1999. p. $179-207$.

Asher, JE. Observation and Theory on X-Disease or Needle Dieback. Report, Arrowhead Ranger District, San Bernardino National Forest, USDA Forest Service, 1956

Bytnerowicz A, Fenn ME, Miller PR, Arbaugh MJ. Wet and dry pollutant deposition to the mixed conifer forest: chapter 11. In: Miller PR, McBride JR, editors. Oxidant air pollution impacts in the montane forests of Southern California. Ecol. Studies, vol. 134. New York (NY): Springer; 1999. p. 270-87.

California Air Resources Board (CARB). Final Report No 95-329, Sacramento, CA, 1998.

Fenn ME, Poth MA. Temporal and spatial trends in stream water nitrate concentrations in the San Bernardino Mountains, Southern California. J Environ Qual 1999;28:822-36.
Fenn ME, Poth MA, Johnson DW. Evidence for nitrogen saturation in the San Bernardino Mountains in Southern California. For Ecol Manag 1996;82:211-30.

Grulke NE. Physiological responses of ponderosa pine to gradients of environmental stressors. In: Miller PR, McBride JR, editors. Oxidant air pollution impacts in the montane forests of Southern California. Ecol. Studies, vol. 134. New York (NY): Springer; 1999. p. 126-63.

Grulke NE, Balduman L. Deciduous conifers: High $\mathrm{N}$ deposition and $\mathrm{O}_{3}$ exposure effects on growth and biomass allocation in ponderosa pine. Water Air Soil Pollut 1999;116:235-48.

Grulke NE, Andersen CP, Fenn ME, Miller PR. Ozone and nitrogen deposition reduces root biomass of ponderosa pine the San Bernardino Mountains, California. Environ Pollut 1998;103:63-73.

Miller, PR, Elderman, MH, editors. Photochemical Oxidant Air Pollution Effects on a Mixed Conifer Forest Ecosystem. Report \# EPA 600/3-77104, U.S. Environmental Protection Agency; 1977.

Miller PR, McBride JR, editors. Oxidant air pollution impacts in the montane forests of Southern California. Ecol. Studies, vol. 134. New York (NY): Springer; 1999. 417 pp.

Miller PR, Parmeter JR, Taylor OC, Cardiff EA. Ozone injury to the foliage of Pinus ponderosa. Phytopathology 1963;53:1072-6.

Miller, PR, Taylor, OC, Wilhour, RG. Oxidant air pollution effects on a western coniferous forest ecosystem. Research Brief, EPA 600/D-82276, U.S. Environmental Protection Agency, Corvallis, OR; 1982.

Miller PR, McBride JR, Schilling SL, Gomez AP. Trend of ozone damage to conifer forests between 1974 and 1988 in the San Bernardino Mountains of Southern California. Proc. Air Pollution Effects on Western Forests, 32nd Annual Meeting, Air and Waste Manage Assoc, 1989.

Minnich RA. Vegetation, fire regimes, and forest dynamics. In: Miller PR, McBride JR, editors. Oxidant air pollution impacts in the montane forests of Southern California. Ecol. Studies, vol. 134. New York (NY): Springer; 1999. p. 44-80.

Minnich RA, Barbour MG, Burk JH, Fernau RF. Sixty years of change in conifer forests of the San Bernardino Mountains: reconstruction of Californian mixed conifer forests prior to fire suppression. Conserv Biol 1993;9:902-14.

Richards BL, Taylor OC, Edmunds GF. Ozone needle mottle of pine in Southern California. J Air Pollut Control Assoc 1968;18:73-7.

Takemoto BK, Bytnerowicz A, Fenn ME. Current and future effects of ozone and atmospheric nitrogen deposition on California's mixed conifer forests. For Ecol Manag 2001;144:159-73.

Tausz M, Bytnerowicz A, Weidner W, Arbaugh MJ, Padgett P, Grill D. Changes in free-radical scavengers describe the susceptibility of Pinus ponderosa to ozone in southern Californian Forests. Water Air Soil Pollut 2000;116:249-54. 